\title{
A controlled trial of carbenoxolone sodium capsules in the treatment of duodenal ulcer
}

\author{
R. D. MONTGOMERY, I. H. LAWRENCE, D. J. MANTON, K. MENDL, \\ AND PAMELA ROWE \\ From the East Birmingham Hospital, Birmingham
}

Carbenoxolone sodium is an effective agent promoting the healing of chronic gastric ulcers (Doll, Hill, Hutton, and Underwood, 1962; Doll, Hill, and Hutton, 1965; Horwich and Galloway, 1965; Turpie and Thomson, 1965). The drug is readily absorbed from the stomach and is largely excreted in bile (Iveson, Parke, and Williams, 1966). It is believed to have a local effect on the gastric mucosa through its strong affinity for mucus, and there is indirect evidence that it may enhance mucus secretion (Goodier, Horwich, and Galloway, 1967; Dean, 1968). When administered in tablet form it has no demonstrable effect on the course of duodenal ulceration.

Preliminary radiological experiments with a positioned-release capsule ${ }^{1}$ suggested that rupture could consistently be obtained as the capsule passed through the pylorus, releasing its contents into the duodenum (Galloway, 1968). Good short-term results were reported by Craig, Hunt, Kimerling, and Park (1967) with the use of these capsules in duodenal ulcer.

We report our findings in a controlled trial of 44 patients with duodenal ulcer followed up for six months.

\section{METHODS}

The conduct of the trial was as previously described (Lawrence, Manton, Mendl, and Montgomery, 1968). All patients under 70 years of age were accepted who presented with typical symptoms of at least three months' duration, who were not confined to bed, and who had the radiological appearances of active, uncomplicated duodenal ulceration. Inpatients were excluded, as were those whose ulcer was revealed as a result of haemorrhage, perforation or stenosis, and those who were symptomless when due to enter the trial.

After a barium examination the patient was allocated, according to a randomized series, either to a 'carbenoxolone' or a 'control' group. Some comparative clinical data for the two groups are summarized in Table I.

Fifty-one patients entered the trial but seven were

${ }^{1}$ Duogastrone, Berk Pharmaceuticals.

\section{TABLE I}

DATA FOR DUODENAL ULCER PATIENTS IN CARBENOXOLONE AND CONTROL GROUPS

\begin{tabular}{lcc} 
& $\begin{array}{l}\text { Carbenoxolone } \\
\text { Group }\end{array}$ & $\begin{array}{c}\text { Control } \\
\text { Group }\end{array}$ \\
\hline $\begin{array}{l}\text { Total number of cases } \\
\text { Sex (M:F) }\end{array}$ & 22 & 22 \\
$\begin{array}{l}\text { Mean age (yr) } \\
\text { Mean duration of history (yr) }\end{array}$ & $19: 3$ & $17: 5$ \\
$\begin{array}{l}\text { Mean work loss during preceding } 12 \\
\text { months (days) }\end{array}$ & 40 & 45 \\
$\begin{array}{l}\text { Family history of peptic ulcer in } \\
\text { parents or siblings (cases) }\end{array}$ & 20 & $9 \cdot 5$ \\
$\begin{array}{l}\text { Noticeable anxiety or depression } \\
\text { (cases) }\end{array}$ & 10 & 21 \\
$\begin{array}{l}\text { Mean no. of cigarettes smoked per } \\
\text { day }\end{array}$ & 4 & 10 \\
$\begin{array}{l}\text { (a) before trial } \\
\text { (b) during trial }\end{array}$ & 16 & 3 \\
\end{tabular}

withdrawn, five from the control group and two from the carbenoxolone group. Four of these defaulted after six weeks, two were found to have pyloric rather than duodenal ulcers, and in the seventh case an additional gastric ulcer was present. Twenty-two cases remained in each group.

All patients were advised to avoid fasting, very large meals or hurried meals, largely to avoid cooked fats, and to reduce their smoking habits. None was confined to bed at any stage. Both groups were followed up at three, six, and 12 weeks, and at six months. Radiological examination was repeated after 12 weeks. Serum electrolytes were estimated in 17 of the carbenoxolone group before and after therapy.

The carbenoxolone group received carbenoxolone sodium positioned-release capsules, $50 \mathrm{mg}$ four times a day, taken 20 to 30 minutes before a meal, for six weeks. Antacids, particularly Nulacin tablets, were prescribed to be taken in addition if required for relief of symptoms. The control group was treated on a basis of aluminium hydroxide gel in regular doses with Nulacin tablets as required, unless they or their practitioners expressed a preference for other forms of antacid.

In short, traditional antacid therapy was applied according to symptoms in both groups. When patients were found to be free of symptoms and tenderness, they were advised subsequently to take antacids only as required.

A preliminary review of the first eight cases in each 
group suggested that there might be a clinical advantage in the carbenoxolone group at six weeks which was not maintained at 12 weeks. It was decided, therefore, to modify the trial so that henceforward the carbenoxolone cases continued to take one capsule twice a day during the second six weeks.

Clinical assessment was by a simple scale based on the severity of symptoms ( 0 to 4 points) and the severity of local tenderness over the duodenum ( 0 to 3 points) (Table II). Radiological assessment was confined to whether the

\section{TABLE II}

CLINICAL ASSESSMENT SCORING SYSTEM FOR ABDOMINAL PAIN AND LOCAL TENDERNESS

\begin{tabular}{lclc} 
Pain & Score & Tenderness & Score \\
\hline Mild, occasional, readily relieved & 1 & Mild & 1 \\
Mild, occurring most days & 2 & Moderate & 2 \\
$\begin{array}{l}\text { Moderate, frequent, including } \\
\text { night pain }\end{array}$ & 3 & Marked & 3 \\
Severe, radiating, poorly relieved & 4 & &
\end{tabular}

ulcer was healed, improved, unchanged, or worse. The radiologists were unaware of the patient's treatment group. The clear demonstration of an ulcer crater was not required for the initial diagnosis in all cases since several of the most typical cases had severe duodenal irritability and deformity in which the identification of a crater site was unreliable. In fact a crater was defined with reasonable certainty in 17 of the 22 carbenoxolone cases and in 16 of the 22 controls. Of the remainder, five patients subsequently came to operation and an active ulcer was confirmed in all of them.

\section{RESULTS}

The clinical results are summarized in Table III. There appeared to be an advantage in the carbenoxolone group at six weeks, 13 carbenoxolone cases and eight controls being clinically 'healed' at this time, ie, they were symptom-free and had no local tenderness At 12 weeks, the clinical scoring was not significantly in favour of carbenoxolone, and only eight carbenoxolone cases were clinically 'healed' compared with nine controls. The second batch of patients who took carbenoxolone twice a day during their second six weeks fared no better than the initial eight cases.

Three patients occasionally vomited intact capsules several hours after ingestion. Several also
TABLE IV

CASES ClinicAlly 'HEALED'

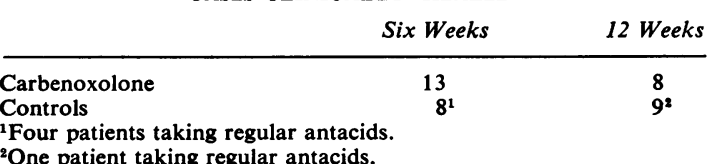

${ }^{2}$ One patient taking regular antacids.

admitted to some difficulty in timing the dose 20 to 30 minutes before a meal, particularly in the middle of a working day.

The radiological assessment after 12 weeks (Table V) showed healing of the ulcer in five patients on carbenoxolone and in one control, while four patients on carbenoxolone and two controls showed definite improvement. (Four patients defaulted from their repeat radiograph.) These differences are not of statistical significance. Of the six healed cases, three had a completely normal duodenal picture and the other three showed persisting deformity without a crater and without spasticity. A crater had previously been demonstrable in five of the six.

\section{TABLE V}

RADIOLOGICAL ASSESSMENT AT 12 WEEKS

$\frac{\text { Carbenoxolone }}{21 \text { Cases }}-\frac{\text { Controls }}{19 \text { Cases }}$

\begin{tabular}{lrr}
\hline 'Healed' & 5 & 1 \\
Improved & 4 & 2 \\
Unchanged & 12 & 15 \\
Worse & 0 & 1
\end{tabular}

Nineteen carbenoxolone cases and 17 of the controls were reviewed after six months. Six in each group had been referred for surgical treatment because of the severity and chronicity of symptoms. Of the remainder, seven patients in the carbenoxolone group and nine in the control group were free of symptoms. Five of these carbenoxolone cases and two of the controls had shown radiological healing or improvement at 12 weeks.

SIDE EFFECTS As previously reported (Lawrence et al, 1968), clinical evidence of fluid retention together with mild hypokalaemia developed in two

TABLE III

CLINICAL ASSESSMENT SCORES (SEE TABLE II) IN 22 CARBENOXOLONE CASES AND 22 CONTROLS

\begin{tabular}{|c|c|c|c|c|c|c|}
\hline \multirow[t]{2}{*}{ Series } & \multicolumn{3}{|c|}{ Carbenoxolone Cases } & \multicolumn{3}{|c|}{ Controls } \\
\hline & Initial & Six Weeks & 12 Weeks & Initial & Six Weeks & 12 Weeks \\
\hline $\begin{array}{l}\text { First ( } 8 \text { cases each) } \\
\text { Second ( } 14 \text { cases each) }\end{array}$ & $\begin{array}{l}31 \\
65\end{array}$ & $\begin{array}{r}3 \\
15\end{array}$ & $\begin{array}{l}10 \\
26\end{array}$ & $\begin{array}{l}29 \\
58\end{array}$ & $\begin{array}{l}13 \\
32\end{array}$ & $\begin{array}{r}8 \\
29\end{array}$ \\
\hline Total & 96 & 18 & 36 & 87 & 45 & 37 \\
\hline
\end{tabular}


patients taking carbenoxolone capsules, one of whom also developed hypertension.

\section{DISCUSSION}

The clinical results at six weeks in this series were comparable to those reported by Craig et al (1967) after one month's treatment. However, at 12 weeks and six months no advantage for carbenoxolone was clinically apparent. It is possible that the results would have been better if carbenoxolone in the full initial dosage had been continued for the whole 12 weeks, but there is no positive evidence that the small dose in the second six weeks was beneficial.

With regard to the radiological findings, minor degrees of improvement, such as reduction in spasticity, were disregarded in this analysis as being of doubtful reliability, and the changes in the nine carbenoxolone cases and three controls described as healed or improved can be accepted as beyond reasonable doubt. Seven out of these 12 cases were symptom-free (without operation) after six months, as compared to only eight out of 28 whose radiographs at 12 weeks were unchanged or worse, which is further evidence that the $x$-ray findings indicated an advance towards healing in these cases. However, as the differences in the two groups do not reach statistical significance, our conclusion is that any possible benefit from carbenoxolone capsules is too slight and transient to be of practical value when administered in this dose regimen. The clinical evidence suggested that more prolonged therapy in 'full' doses might be effective.

There are several reasons why a therapeutic effect of carbenoxolone in duodenal ulcer should be difficult to achieve or maintain. First, there is the doubt as to how many capsules will release the drug at the pylorus in the correct manner (Langman, 1968). Secondly, even if this occurs, the rapidity with which substances pass through the duodenum makes it very difficult to achieve a sustained effect from a drug which is believed to have a local action, even if it has a strong affinity for mucus. Thirdly, even if this is achieved, enhancement of the "mucous barrier' may be relatively less effective in the case of duodenal ulceration, where the opposing effect of acidity is probably the major factor in chronicity, than in gastric ulcers where a failure of the mucosal defences may be relatively more important.

\section{SUMMARY}

A controlled trial of carbenoxolone sodium positioned-release capsules (Duogastrone) was performed on a randomized series of patients with radiologically proven duodenal ulcer, all of whom had symptoms on entering the trial, but had not been confined to bed. Forty-four patients completed the trial. Twenty-two control patients received dietary advice and were treated with regular doses of antacids. The other 22 patients additionally received Duogastrone $50 \mathrm{mg}$ four times a day before meals for six weeks. All were assessed at three, six, and 12 weeks, when radiographs were repeated, and there was a clinical follow-up after six months.

Review of the first eight cases in each group suggested that there might be a clinical advantage in the carbenoxolone group at six weeks which was not maintained at 12 weeks. In the remainder of the trial, therefore, the carbenoxolone patients continued to take one capsule twice a day for the second six weeks.

Clinical analysis showed no significant difference between the carbenoxolone or control groups after 12 weeks or after six months. On 'blind' radiological assessment, nine cases on carbenoxolone showed healing or improvement, compared with three in the control group, but this difference does not reach statistical significance.

We are indebted to Dr S. Gottfried, of Biorex Laboratories Limited, and Mr F. M. Sullivan, of the Department of Pharmacology, Guy's Hospital Medical School, for their assistance.

\section{REFERENCES}

Craig, O., Hunt, T., Kimerling, J. J., and Park, D. V. (1967). Carbenoxolone in the treatment of duodenal ulcer. Practitioner, 199, 109-111.

Dean, A. C. B. (1968). Protective effect of carbenoxolone in druginduced lesions of the stomach. In $A$ Symposium on Carbenoxolone Sodium 1967, pp. 33-39. Edited by J. M. Robson and F. M. Sullivan. Butterworths, London.

Doll, R., Hill, I. D., and Hutton, C. F. (1965). Treatment of gastric ulcer with carbenoxolone sodium and oestrogens. Gut, 6, 19-24.

,,--- , and Underwood, D. J., II (1962). Clinical trial of a triterpenoid liquorice compound in gastric and duodenal ulcer. Lancet, 2, 793-796.

Galloway, R. (1968). Development of the duogastrone capsule. In A Symposium on Carbenoxolone Sodium 1967, pp. 203-208. Edited by J. M. Robson and F. M. Sullivan. Butterworths, London.

Goodier, T. E. W., Horwich, L., and Galloway, R. W. (1967). Morphological observations on gastric ulcers treated with carbenoxolone sodium. Gut, 8, 544-547.

Horwich, L., and Galloway, R. (1965). Treatment of gastric ulceration with carbenoxolone sodium: clinical and radiological evaluation. Brit. med. J., 2, $1274-1277$.

Iveson, P., Parke, D. V., and Williams, R. T. (1966). The metabolic fate of ${ }^{14} \mathrm{C}$ carbenoxolone in the rat Biochem. J., 100, 28P.

Langman, M. J. S. (1968). Carbenoxolone sodium. Gut, 9, 5-6.

Lawrence, I. H., Manton, D. J., Mendl, K., and Montgomery, R. D. (1968). A three-months' assessment of duogastrone therapy in chronic duodenal ulcer. In A Symposium on Carbenoxolone Sodium 1967, pp. 217-223. Edited by J. M. Robson and F. M. Sullivan. Butterworths, London.

Turpie, A. G. G., and Thomson, T. J. (1965). Carbenoxolone sodium in the treatment of gastric ulcer with special reference to sideeffects. Gut, 6, 591-594. 